\title{
Online Communication Tools in Biochemistry Teaching
}

\author{
Ferreira, A. O., Lima, C. A., Balbino, R. R., Hornink, G.G. \\ Bioquímica, ICEx, Unifal-MG, MG, Brazil
}

The online communication tools enable new ways of learning, especially the forums in the context of online courses, and the understanding of interactions and collaborations in the forums can improve them. The study aimed to analyze the online relationships, as well as obtaining evidence of the use of other learning tools in a biochemistry subject, focusing on how students use the tool forum and its contribution to learning. The study was carried out from data pre and post course questionnaires as well as log of environment access and discussion forum. The forums have been restructured and systematized for analysis and creating discursive flows between statements. The questionnaires showed the central role of forum and wiki for learning, the importance of interactions, which was highlighted by the forum analysis. The results indicate that one of the ways to improve online biochemistry teaching is to stimulate interactive activities, participatory moderation and pedagogical support by tutors and mentors, also encouraging and creating strategies to collaboration of students to solve problems and to collaborative knowledge construction.

Keywords: online biochemistry teaching, collaborative forums, online communication tools

Supported by: Unifal-MG 
This document was created with Win2PDF available at http://www.win2pdf.com. The unregistered version of Win2PDF is for evaluation or non-commercial use only. This page will not be added after purchasing Win2PDF. 